\title{
Study of Additive Manufacturing for the Aircraft Industry
}

\author{
Yogesh Kumar Mall, Md. Sajid, Ramineni Jitendra Sai, Rambarki Deepak, Guravtar Singh Mann
}

\begin{abstract}
This is a review paper on $3 D$ printing, its significance, and future scope in the aircraft industry.In this article, additive manufacturing is compared with traditional manufacturing in the context of the aircraft industry that gives more accurate knowledge about how additive manufacturing is more effective in terms of cost-cutting, waste prevention, customization, and large-scale production. We will go into the need for 3D printing technology, how it has taken in step over other manufacturing process and are being used for a host of different applications. The paper gives sufficient information about various types of material used in additive manufacturing with the applications, examples, requirements, and process moreover some overview of limitations as well. How Rapid tooling is used with a different process to reduce time and get more productive and efficient parts for the aircraft industries. The use of $3 D$ printing technology in the aircraft industry plays a major role and gained immense applications. It has greatly affected the production line due to its flexibility and ease of production. It is capable of producing intricate parts, a more resilient and lightweight structure that achievesa weight reduction of $40-60 \%$, subsequently result in a leaner cost structure, material saving, and lower fuel consumption.The last section deals with the future scope of additive manufacturing in the aircraft industry with various parameters design aircraft wings, complex design parts, additive manufacturing in space. More companies and the aerospace industry continue to see the value of $3 D$ printing and begin developing on-site $3 D$ printing operations and investing in the technology.
\end{abstract}

Keywords: Additive Manufacturing, aerospace, rapid tooling, resin, surrogates

\section{INTRODUCTION}

3D printing is a digital fabrication process that can create a physical object of any shape or geometry typically by laying down many successive thin layers of material. The technology involves the manipulation of $3 \mathrm{D}$ objects in digital format and manufacturing physical form by adding layer by layer of materials. It is called 3D printing because it works similarly to that of an ordinary printer where binder material is deposited onto a powder bed with inkjet printer heads layer by layer.

Revised Manuscript Received on December 25, 2020.

* Correspondence Author

Yogesh Kumar Mall*, Mechanical Engineering, B.Tech(Hons.) Lovely Professional University, Phagwara (Punjab)

Md. Sajid, Mechanical Engineering, B.Tech(Hons.) Lovely Professional University, Phagwara (Punjab)

Ramineni Jitendra Sai, Mechanical Engineering, B.Tech(Hons.) Lovely Professional University, Phagwara (Punjab)

Rambarki Deepak, Mechanical Engineering, B.Tech(Hons.) Lovely Professional University, Phagwara (Punjab)

Guravtar Singh Mann, Associate Professor Industrial and Production Engineering M. Tech Industrial and Production Engineering (Dr. B. R Ambedkar NIT, Jalandhar), B.Tech Mechanical(PTU Jalandhar)

(c) The Authors. Published by Blue Eyes Intelligence Engineering and Sciences Publication (BEIESP). This is an open access article under the CC BY-NC-ND license (http://creativecommons.org/licenses/by-nc-nd/4.0/)
It differs from the traditional subtractive manufacturing method where the removal of material takes place to create something. Thus it is also known as additive manufacturing. There is a variety of printing technology (process) available to create $3 \mathrm{D}$ objects. The major difference among these processes is in the way layers are deposited and the initial form of raw material that is used. According to the ASTM group, 3D printing technology is mainly classified into seven groups including material extrusion, sheet lamination, direct energy deposition, powder bed fusion, binding jetting, direct energy deposition, material jetting, and vat photopolymerization. None of the technology fits all the applications because each of them has targeted applications. Like any manufacturing process, 3D printing requires highquality materials and can produce fully functional parts in a wide range of materials including metals, ceramic, plastic, and composites. Now a day's 3D printing technologies are being used for a host of different applications. It has been increasingly used for mass customization, production of any type of open-source design in the field of the automotive industry, aerospace industry, agriculture, and healthcare. It allows a more flexible and responsive manufacturing process as well as greater quality control with higher production speed and lower cost. It can influence the logistics of a company. At the same time, it puts certain limitations, for example,the adoption of 3D printing will reduce the use of manufacturing labor thus will have an adverse effect on the economy of a country that relies on a large number of low labor skills jobs. It can be used for the wrong intend purpose for printing objects such as knives guns and dangerous items. Thus the use of 3D printing should be limited to only certain people to prevent terrorism and act of crime.

\section{COMPARISON OF TECHNOLOGY: ADDITIVE MANUFACTURING VS TRADITIONAL MANUFACTURING}

\section{A. Prototype production}

The traditional manufacturing process for making a new design or product requiresretooling and production linesbesides some cases require a new tool that takes a lot of time and money to fulfill the criteria. while in the additive manufacturing process is CAD (computer-aided design) that only need to design prototype and go directly to the manufacturing process which reduces wastage of time on retool and other processes. additionally, it saves material and labor costs. So, prototype production in additive manufacturing method has clear as over the traditional manufacturing method. 


\section{Study of Additive Manufacturing for the Aircraft Industry}

\section{B. Waste Prevention}

Traditional manufacturing process such as machining, molding, joining often require extra material to process the production for example in injection molding need extra material to fulfill the mold, in sheet metal assembly process needs extra material to make holes on it and extra material is called scrap that is waste of material. However, it is recyclable but this needs extra effort in terms of time and labor that add cost to the process. The traditional manufacturing process needs to manufacture each part of components individually that consume time and increase material wastage whereas in $3 \mathrm{D}$ printer it prints the whole component at a single place together that reduce the time and wastage of material. Furthermore, additive manufacturing is the addition of material to create a component. it only usesa material that comes through the extruder of the printer and that material is used in the actual assembly of the product, so wastage of material is very less.

\section{Large scale production}

After prototyping phases further process to manufacture the product on a large-scale $3 \mathrm{D}$ printer is generally less, efficient and reliable for this because it is the addition of material to one layer to another layer and it can only assemble One layer at a time and for further layers are only assemble to previous one layer so for this process it takes time. However, it does not need to retool the production lines. For example, if we need to create a pair of a nutcracker, it took nearly three hours, but in the traditional manufacturing process by injection molding, can allow dozens or hundreds of nutcrackers at the same amount of time. So currently for making a small object through an additive manufacturing process. It can consume more time than the traditional manufacturing process. It is difficult to compete with traditional manufacturing speeds for largescale production.

\section{Cost-cutting for complexity and supply chain}

In the traditional manufacturing method for making a complex construction needs very high precision and skilled worker especially for assembly that it increases the cost of the product whereas additive manufacturing process it manufactures the whole component in one process, and all process is done by the $3 \mathrm{D}$ printer only before assembly, hence it reduces the Cost of Products. Traditional Supply Chain is always changing with time for Improve the Chain but still, it Contains some inefficiencies such as Transportation cost, Complex Distribution Network, long lead time, and dependencies of Economics scale. However, 3D Printer is contrary to the above inefficiencies because of local manufacturing and distribution that reduces significantly cost of transport and it also reduced a complex distribution network due to local manufacturing and distribution.

\section{E. Customization and Equipment required}

Until getting satisfaction it is possible to make an unlimited number of changes in the product. In traditional manufacturing methods, there are a large number of identical products for customization and industries are providing a small room for customization. However, additive manufacturing is very close to idle for customization it is not required big space because it combines the manufacturing and assembly process at a single stage. For example, a company is using this customization in normal life stages he is manufacturing earbuds for individual users for perfect fitting on his years. The traditional manufacturing process to make a single product often requires several steps such as turning, milling, drilling to create finished metal parts, whereas additive manufacturing handles all the creation on a single stage that helps to reduce time labor cost and complexity, and required space. Traditional manufacturing for entrepreneurship of for developing new product needs in entire factory setup or retooling the tools. However, additive manufacturing just needs a single piece of equipment that is a $3 \mathrm{D}$ printer with help of these easily develop the whole product without any high investment of factory setup.

\section{CRITICAL ATTRIBUTES AND SIGNIFICANT APPLICATIONS OF ADDITIVE MANUFACTURING IN AIRCRAFT INDUSTRY}

With the ability to transform raw materials without having to convert them into 3D forms, Additive manufacturing helps to elaborate in the aircraft industry. It is especially considering the constraints of the inventory and supply chains and the need for just in time output occurs. In addition, for more complex designs materials, and performance, the aircraft industry has been considering the potential use of Additive Manufacturing for aircraft part production, including various hinges, braces, interior parts as well as the fuel usage and light fuel usages.

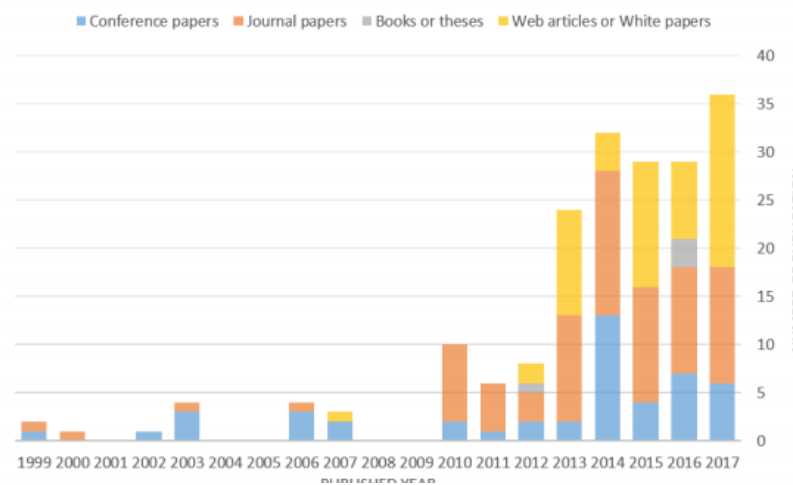

Fig.1. Publication trends for aerospace

Seven classes of AM processes can be classified into powde $r$ bed fusion, binder jetting, direct energy deposition, extrusi on, jetting, sheet lamination, and vat photopolymerization. T he most widely used techniques are selective laser sintering, selective laser melting, electron beam melting, stereolithogr aphy, printing, fused deposition modeling,and direct metal d eposition, while metals, polymers, ceramics, and composites are of different combinations.

\section{A. Mixed materials}

To make stronger materials allowing for possible selective variation of material composition across the product to main is a key attribute of additive manufacturing. Although the full potential of this function has to be realized there has been some progress in embedding conductive sensors and other devices into printed parts the use of multi-material printing technology is limited in the sense of the aircraft industry.






\section{B. Complex geometry}

Multidisciplinary design optimization, especially in aerospa ce engineering, is widely applied in most engineering indust ries. All design variables and constraints, such as material an d structural integrity, aerodynamics, weight, durability, deve lopment, sustainability, sustainability, and cost, need to be c arefully considered by engineers because of the stringent cer tification requirements faced by the aerospace industry.

\section{Optimal Design Solution}

Weight reduction is a key point of increased efficiency and productivity inthe aircraft industry. New geometries such as cellular structures, lattice, honeycomb, and streamlined structures with bionic character may improve the overall effectiveness of the aircraft. In addition, optimize design also reduces operating costs during the assembly and maintenance of aircraft. The advantage of an additive manufacturing design that is difficult to construct cannot now be deviated by conventional methods.

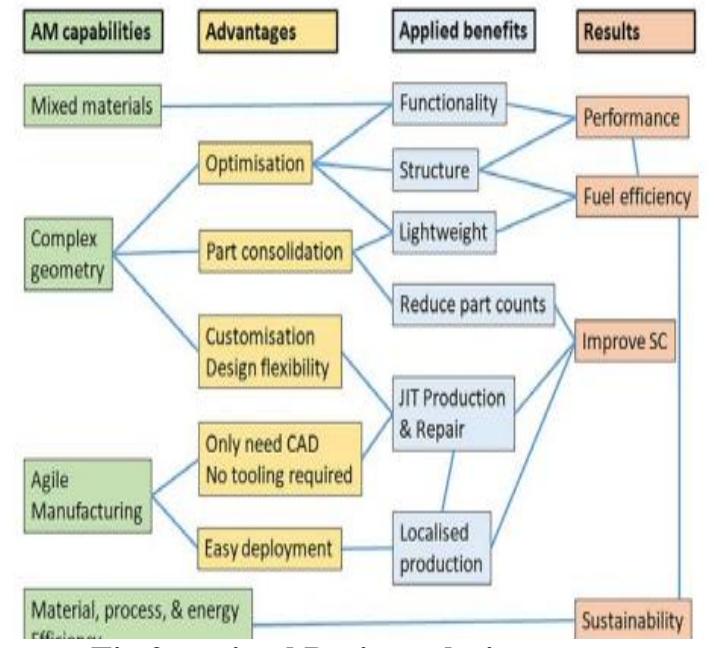

Fig.2. optimal Design solution

\section{D PRINTING MATERIAL AND LIMITATIONS FOR AEROSPACE APPLICATIONS}

Common $3 d$ printing uses in the aircraft industry

\section{A. Jigs and fixtures}

There are big benefits for some of the more permanent 3D printing applications such as producing jigs and fixtures. Businesses have 3D printed hundreds of fixtures, manuals models, and gauges for each aircraft, typically with cost and lead times production of 62 to 90 percent compared to the other method of production.

\section{B. Surrogates}

Surrogates are components of the placeholder that represent components that are subsequently assembled in final assemb lies used in production. Surrogates are typically used for pla nning. NASA and several air force bases commonly use the surrogate components on the factory floor.

\section{High detail visual prototypes}

Material Jetting 3D printing is capable of creatingdesigns si milar to injection molding with a surface finish. These visua lly appealing models allow designers before production choi ces to gain a greater understanding of the shape and fit of a $p$ art.As we have studied 3D printing is also called Additive
Table -I:3D Printing material with process and requirement

\begin{tabular}{|c|c|c|c|c|}
\hline $\begin{array}{l}\text { Applicati } \\
\text { ons }\end{array}$ & $\begin{array}{l}\text { Exampl } \\
\text { e }\end{array}$ & $\begin{array}{l}\text { Requirem } \\
\text { ents }\end{array}$ & Process & $\begin{array}{l}\text { Materia } \\
\text { I }\end{array}$ \\
\hline $\begin{array}{l}\text { Engine } \\
\text { compartm } \\
\text { ent }\end{array}$ & $\begin{array}{l}\text { Tarmac } \\
\text { nozzle } \\
\text { bezel }\end{array}$ & $\begin{array}{l}\text { Heat } \\
\text { resistant } \\
\text { functional } \\
\text { parts }\end{array}$ & SLS & $\begin{array}{l}\text { Glass- } \\
\text { filled } \\
\text { Nylon }\end{array}$ \\
\hline $\begin{array}{l}\text { Cabin } \\
\text { accessorie } \\
\text { s }\end{array}$ & $\begin{array}{l}\text { Console } \\
\text { control } \\
\text { part }\end{array}$ & & & \\
\hline Air ducts & $\begin{array}{l}\text { Airflow } \\
\text { ducting }\end{array}$ & $\begin{array}{l}\text { Customize } \\
\mathrm{d} \\
\text { functional } \\
\text { knobs }\end{array}$ & SLA & $\begin{array}{l}\text { Standard } \\
\text { Resin }\end{array}$ \\
\hline $\begin{array}{l}\text { Full-size } \\
\text { panels }\end{array}$ & $\begin{array}{l}\text { Seat } \\
\text { backs \& } \\
\text { entry } \\
\text { doors }\end{array}$ & $\begin{array}{l}\text { Flexible } \\
\text { ducts and } \\
\text { bellow } \\
\text { directors }\end{array}$ & SLS & $\begin{array}{l}\text { Nylon } \\
12\end{array}$ \\
\hline $\begin{array}{l}\text { Casted } \\
\text { metal } \\
\text { parts }\end{array}$ & $\begin{array}{l}\text { Brackets } \\
\text { and door } \\
\text { handles }\end{array}$ & $\begin{array}{l}\text { Flexible } \\
\text { ducts and } \\
\text { bellow } \\
\text { directors }\end{array}$ & SLS & $\begin{array}{l}\text { Nylon } \\
12\end{array}$ \\
\hline $\begin{array}{l}\text { Metal } \\
\text { componen } \\
\text { ts }\end{array}$ & $\begin{array}{l}\text { Suspensi } \\
\text { on } \\
\text { wishbon } \\
\text { e \& GE } \\
\text { Jet } \\
\text { Engine }\end{array}$ & $\begin{array}{l}\text { Large parts } \\
\text { with } \\
\text { smooth } \\
\text { surface } \\
\text { finish }\end{array}$ & SLA & $\begin{array}{l}\text { Standard } \\
\text { Resin }\end{array}$ \\
\hline Bezels & $\begin{array}{l}\text { Dashboa } \\
\text { rd } \\
\text { interface }\end{array}$ & $\begin{array}{l}\text { Metal parts } \\
\text { cast using } \\
\text { 3D printed } \\
\text { patterns }\end{array}$ & $\begin{array}{l}\text { SLA \& } \\
\text { Material } \\
\text { Jetting }\end{array}$ & $\begin{array}{l}\text { Castable } \\
\text { Resin or } \\
\text { Wax }\end{array}$ \\
\hline Lights & $\begin{array}{l}\text { Headlig } \\
\text { ht } \\
\text { prototyp } \\
\text { es }\end{array}$ & $\begin{array}{l}\text { Consolidat } \\
\text { ed, } \\
\text { lightweight } \\
\text {, functional } \\
\text { metal parts }\end{array}$ & $\begin{array}{l}\text { DMLS/S } \\
\text { LM }\end{array}$ & $\begin{array}{l}\text { Titaniu } \\
\text { m or } \\
\text { Alumini } \\
\text { um }\end{array}$ \\
\hline
\end{tabular}

Manufacturing, used for the construction of a threedimensional object using a Prototype or Model designed using coordinates/dimensions by computer controls.3D printable models can be created using Computer-aided Design and the files have to be saved in STL (Stereolithographic File Format) for getting good-finished Surface models. Before getting the File in STL format it has to be examined for various errors like Holes, Face normal, Manifold errors, etc.

\section{Materials for 3D Printing}

As of traditionally in 3D printing Polymers are used for printing, which makes the process easy and handling polymeric materials, due to rapidly evolving not only polymers were used even ceramics and metals were being used which is the best option for manufacturing. The materials used in 3D printing are chosen according to the product. The process is a layer by layer fabrication which gives a solid modeled finish.

Published By:

Blue Eyes Intelligence Engineering and Sciences Publication

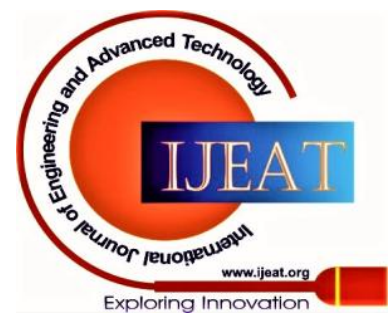




\section{Study of Additive Manufacturing for the Aircraft Industry}

The Three-dimensional layer is controlled by the deposition rate set by the operator and stored in a file. This makes the strength, shape, volume, texture of the product. So basically, all these would make with the exact design of the product needed using the STL design file which can give a product with no defect from all the angles, sides.

\section{E. Various materials used in 3D Printing:}

Plastic: It is the most common and the plastic 3D printing products have more demand as this has various properties as the plastic products are made using FDM printers, where the thermoplastic would be melted and molded layer by layer. Not only thermoplastic there are some other materials

- Polycarbonate

- Polyvinyl alcohol Plastic

- $\quad$ Plastic acid

Metals: Theseare the second most used and popular material in the 3D Printing industry. This material is used by the manufacturers who used to make the components for aircraft which made it easy for the manufacturers to save time rather than using the traditional methods. Some others also made jewelry products and many others used this method for making the job easy within no time. Some of the other metals are

- Titanium

- Aluminum

- Gold

- Bronze

- Stainless-Steel

Carbon Fiber: Carbon fiber is a composite that is used as the material used to make plastic products hardener. It is and hardening material in the industry using plastic for making 3D products this layer of carbon fiber even gives the highend finish.

Polymers: we have many commercially available polymers types that have their properties. Polymers are used only if needed by the customer or market needs as many of the daily needs for the common man are being fulfilled using these polymers like electronics, Water bottles, Toys, etc. Polymers having characteristics like High Stiffness, Weight ratio's, Resistance, Mechanical Properties.

Table- II: Materials used in aerospace applications

\begin{tabular}{|l|l|}
\hline Application & Parts \\
\hline Cabin accessories & Controlling parts \\
\hline Engine Components & Nozzles \\
\hline Metal Components & $\begin{array}{l}\text { Suspension, Wishbone, } \\
\text { Jet engine }\end{array}$ \\
\hline Lights & Headlights \\
\hline Cast Metal Parts & Door handles \\
\hline Airtight Panels & Entry Doors \& Windows \\
\hline Air Ducts & Air Flow Duct Pipes \\
\hline
\end{tabular}

\section{F. Material Efficiency}

Parts made of Titanium are very expensive. These materials have a special machining process along with this it takes a very long time for machining also and due to this production of 3D printing using expensive material is highly Effective. Quality of this can be checked even while printing the product and also it is feasible for getting a good layer by layer deposition of material.Due to this efficiency, there are many benefits:

- Low Volume production

- $\quad$ Light Weight

- $\quad$ Easy Replacement of parts

- Wear and tear would be Less

\section{G. Limitations}

3D Printed Material Examination has to be performed with various parameters like strength, resistance, Dimension, Stability, Viscosity, Toughness, conductivity, fatigue resistance, etc. In the load-bearing aspect strength of the printed parts is more important and it is a key aspect even during the examination process. Solidification defects like porosities, cavities, oxidation also are the main examined parts. The mechanical properties of 3D printed parts can be increased by using the fibred powder.

\section{IMPLICATIONS OF 3D PRINTING- EXPECTED PREPOSITIONS}

The cost and processing time is reduced through its suitability for complex materials, fast manufacturing,

\begin{tabular}{|l|l|}
\hline Process Followed & Material Used \\
\hline SLA(Stereolithography) & Resin \\
\hline SLS (Selective laser Sintering) & Glass-Nylon \\
\hline SLM (selective laser melting) & Aluminum/ \\
DMLS (Direct Metal Laser Sintering) & Titanium \\
\hline SLA(Stereolithography) & Resin \\
\hline Material Jetting & Castable resin \\
\hline SLA (Stereolithography) & Standard Resin \\
\hline SLS (Selective Laser Sintering) & Nylon \\
\hline
\end{tabular}

lightweight and less weight tool adjustement.3D printing has enabled aerospace companies to produce complex materials by using advanced techniques that are previously impossible. This reduces the cost and time for the manufacturers. The manufacturing industry has played a main role in making $3 \mathrm{D}$ printing for example for three decades, global manufacturers, like BMW, have been using 3D printing technology. Aerospace is one of the biggest adopters of 3D printing with the industry representing almost a quarter of the market.

Cons of $3 d$ printing

\section{A. Limited Materials}

Although 3D printing may produce articles from a variety of plastics and metals and selection of raw materials available is not exhaustive. This is because not all metals or plastic can be adequately temperature control to format 3D printing.

\section{B. Restricted to build size}

Currently, 3D printers have limited printing chambers that li mit the size of parts that can be printed. After production, an ything greater would need to be printed in separate parts and joined together.

\section{Post-processing}

While large parts need postprocessing, most 3D printed part

Published By:

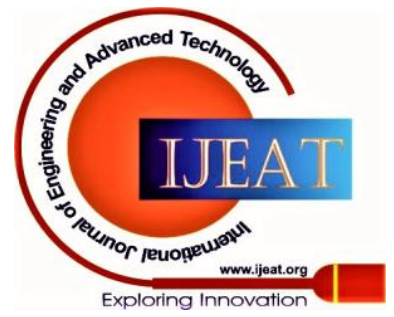


s need some form of cleaning to remove support material fro $m$ the construction and smooth the surface to achieve the ne cessary finish, described above. Water jetting, sanding, a ch emical soak and rinse, air or heat drying, assembly, and others are post-processing methods used.

\section{Reduction in manufacturing job}

The possible reduction in human labor is another problem of 3D technology as much of the output of automated and performed by the printer. However, in order to keep the year economics going many third world countries rely on low and skilled workers and this technology could put these manufacturing jobs at risk by eliminating the need for production abroad.

\section{E. Design inaccuracies}

Another potential problem with 3D printing is directly related to the type of machine or process used with some printers having lower tolerance meaning that final parts may differ from the original design. In a lot of industries 3D printing provides various benefits. However, it is not going to replace past production. It is still an emerging technology with some disadvantages that have to be weighed when selecting a method of product production. Therefore, it needs to be seen by producers product designers as a mechanism to complement traditional production. They will take advantage of their unique ability to refine product design and produce an entirely new product that cannot be different.



Fig.3. Optimize the aerospace part through Additive manufacturing

\section{RAPID TOOLING AND REPAIRING}

Rapid tooling is a process using rapid prototyping techniques and tooling practices that are used together to produce mold. Rapid Tooling is normally carried out using the Traditional Casting process, it uses mainly expandable Prototype Models like Selective Laser Sintering (SLS), Laminated Object Manufacturing (LOM), and stereolithography (SLA). Rapid Tooling has various Applications like Surrogates, Molds, Jigs \& Fixtures, mandrels. It is also an important technical aspect that gives a wide range of opportunities to develop the components of medical uses. It is not only the way for 3D printing the Medical Devices. The existing technologies are evolved subsequently concerning device quality Material selection. Manufacturing technologies Injection molding and Extrusion has standard results. Rapid tooling also allows us to use the fine grades of materials which gives a clear picture of how the parts would be able to get the good choices of material. Many use this rapid tooling to test the parameters of production and ensure they will get the parts filled correctly as expected.
A. Materials used in Rapid Tooling
- Nylon
- Polypropylene
- $\quad$ PA6- High Degree Performance Plastic
- pA12-Low Moisture Performance Plastic
- HDPE- High-Density Polyethylene
- POM- Polyoxymethylene
B. Advantages of Rapid Tooling
- Low Cost for Tooling
- Higher Tool Life
- Less Tooling Time
- $\quad$ Functional Test at any stage of Design
- $\quad$ Process redemptions
- High Volume Manufacturing
- Repeatability

With this rapid tooling, the new era for developing parts products and many others would have a way out to get into existence and also if the product technology is good enough then automatically the demand reach would be high. As the rapid tooling is Domestically used as it can be operatable by people the tooling can be conventional and the efficiency would swift the delivery of parts

\section{Categories of Rapid Tooling}

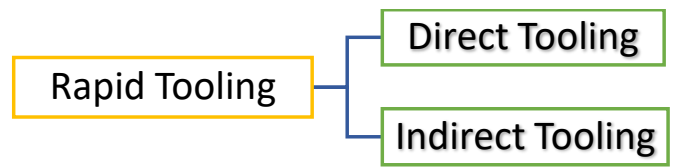

\section{Direct Tooling}

It is used straight for the production of molds that do not require any kind of pattern. The techniques used in this are LENS, Direct AIM, DMLS, laminating tooling, etc.

\section{E. Indirect Tooling}

It is used for the most common types of rapid tooling and prototyping but not for direct prototyping.

\section{F. Repairing}

3D Printing is not only used to create new tools molds but also repairs damaged parts of tools. Many Industrial goods, shipbuilding companies are using processes like Direct Energy Deposition to repair the damaged part

\section{FUTURE OUTLOOK OF 3D PRINTER IN AEROSPACE INDUSTRY}

According to ICF International, additive manufacturing currently covers $0.0002 \%$ of the worldwide manufacturing market in aerospace. If $0.002 \%$ converts, then it comes to about $\$ 150$ billion business parts market. Space companies, such as ICF International forecasting that after the next decade It reaches up to $\$ 200$ billion. Additive manufacturing for the Aerospace industry in the future it's looking very potential and even more promising in many areas.

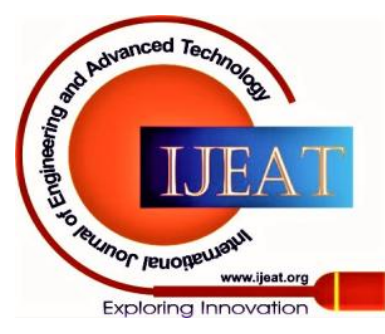




\section{Study of Additive Manufacturing for the Aircraft Industry}

A.

\section{Design Aircraft wings}

Additive manufacturing already adopted by aircraft industries for manufacturing small parts such as table tray hand rest etc. and now industries are looking for large parts such as airplane wing but for now, it is manufacturing large parts to 3D printing have some problems as building internal stress and distortion. To overcome these problems the aircraft industry already started developing new technologies in additive manufacturing. currently,the BAE system developed a technique where they use ultrasonic tools on each layer of printed parts that help to make metal parts stronger and relieve internal stress through it.

\section{B. Complex design parts}

With traditional methods engineers can design a complex part to some extent by various machining processes such as milling, turning, casting, forging, and welding but still have some extent and compromise. To overcome this extent by using various types of plastic, metals, and composite material parts manufactured by additive manufacturing. Additive manufacturing is also helpful for testing and prototypes to check clearance, angles, tolerance without the interference of CNC machining for complex parts.GE (General Electronics) is already started developing the GE9X engine with the help of additive manufacturing that helped design the next-generation Boeing 77X long-haul passenger jet with the help of a 3D printer. Autodesk and Stratasys started to develop a full scale of turboprop engines. So in the future, there is a good probability to develop jet engine parts with additive manufacturing.

\section{Additive manufacturing in space}

NASA is looking for manufacture demand parts in space with additive manufacturing that is going to reduce the cost and time for assembly and other processes. currently, NASA is already using 3D printed parts for space exploration vehicles, but they are developed on earth. Manufacturing parts in a space with help of additive manufacturing some groups are already started working with collaboration with each other. Made in space, Lunar building and NASA are involved and they are testing additive manufacturing in a space station with zero gravity.

\section{Weight Reduction}

For aircraft industries weight is one of the most important factors because if weight is low, then low fuel consumption and low $\mathrm{CO} 2$ emission and less material used means low material cost. Additive manufacturing already developed some important airplane parts with reduced weight up to $60 \%$ with help of improved geometry and optimized lattice structure such as manifold, its weight reduced by $60 \%$ with help of additive manufacturing.

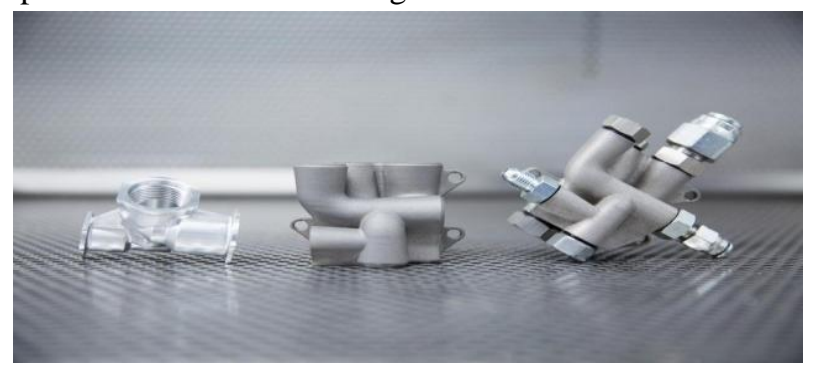

Fig.4. Manifold Weight reduced part by $60 \%$

\section{SUMMARY}

3D printing is a digital fabrication process that can create a physical object of any shape and geometry typically by laying down many successive thin layers of material. It has been increasingly used for mass customization, production of any type of open-source design in the field of the automotive industry, aerospace industry, agriculture, and healthcare. Though it puts certain constraints it has taken in step over traditional manufacturing process due to its simplicity, flexibility, and also on account of lower cost and reduced waste production.Additive manufacturing in the Aircraft industry plays a vital role in productivity in favor of reducing time for complex parts, weight reduction, costcutting, and customizations The aerospace and defense industries contributed $16 \%$ of 3D printing's $\$ 4.9+$ billion global revenues in 2015. From a recent report of research and market, it is found that there is a growth rate of $23 \%$ between 2017 and 2021 in the sector. The technology is capable of producing intricate parts that are more resilient and with a weight reduction of $40-60 \%$. It is found that a single component designed and manufactured by 3D printing, reduces air drag by $2.1 \%$ which in turn reduces fuel cost by $5.41 \%$. the environmental impact of air travel can be minimized subsequently by cutting fuel and limiting emission.after analyzing all parameters and data, it can be forecast that additive manufacturing is going to be taken most of the traditional manufacturing place.Still, some limitations are there in additive manufacturing such as limited material, build size, and design accuracy, but incoming technologies that are already developed by aircraft industries will help to overcome the above limitations. NASA has predicted that future space aircraft can be equipped with a $3 \mathrm{D}$ printer so that scientists can send astronauts digital files to be printed. More companies and the aerospace industry continue to see the value of 3D printing and begin developing onsite 3D printing operations and investing in the technology.

\section{REFERENCES}

1. http://www.sciencedirect.com

2. https://www.researchgate.net/publication/272789911_3D_printing

3. https://blog.grabcad.com/blog/2019/08/27/3d-printing-in-theaerospace-industry

4. https://www.ijert.org/research/a-review-paper-on-3d-printing-aspectsand-various-processes-used-in-the-3d-printing-IJERTV6IS060409.pdf

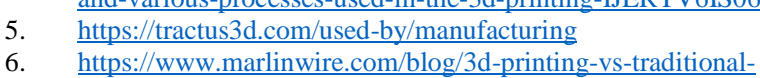
manufacturing

7. https://precious3d.com/traditional-manufacturing-vs-3d-printing

8. https://www.worldfinance.com/infrastructure-investment/3d-printingcannot-completely-replace-traditional-manufacturing-say-experts https://blog.animalventures.com/blog/additive-manufacturing-vstraditional-manufacturing

10. https://www.3dhubs.com/knowledge-base/aerospace-3d-printingapplications

11. https://www.researchgate.net/publication/331482685_Additive_Manu facturing_for_the_Aircraft_Industry_A_Review

12. Aviation G. GE Aviation investing $\$ 27$ million to expand advanced technology efforts in Delaware. 2013; 2:1

13. https://blog-idcuk.com/how-3d-printing-is-transforming-industryaerospace




14. https://www.aerospacemanufacturinganddesign.com/article/3dprintings-impact-on-aerospace

15. https://3dprint.com/190573/aeronautics-automotive-in3dustry

16. https://www.sciencedirect.com/topics/engineering/rapid-tooling

17. https://amfg.ai/2019/12/19/5-ways-3d-printing-complementstraditional-manufacturing

18. https://3dprint.com/26081/3d-printing-aerospace-5-uses

19. https://www.researchgate.net/publication/323404254_3D_Printing_an d its Effect on Outsourcing A Study of the Indian Aircraft Indu stry/fulltext/5a94c270aca27214056756bb/3D-Printing-and-its-Effecton-Outsourcing-A-Study-of-the-Indian-Aircraft-Industry.pdf

20. https://www.researchgate.net/publication/284911958_3D_printing in aerospace and its long-term sustainability

\section{AUTHORS PROFILE}

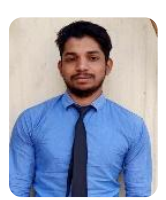

Yogesh Kumar Mall

Department: Mechanical Engineering

Qualification: B.Tech(Hons.) Lovely Professional University, Phagwara (Punjab)

Research Interest: Additive Manufacturing, Operation Management, Design and Manufacturing

\section{Md. Sajid}

Department: Mechanical Engineering

Qualification: B.Tech(Hons.) Lovely Professional University, Phagwara (Punjab)

Research Interest: Combustion and Energy Systems, Dynamic and Control.

\section{Ramineni Jitendra Sai}

Department: Mechanical Engineering

Qualification: B.Tech(Hons.) Lovely Professional University, Phagwara (Punjab)

Research Interest: Supply Chain Management, Production Operations, Research in Autonomous vehicle systems

\section{Rambarki Deepak}

Department: Mechanical Engineering

Qualification: B.Tech(Hons.) Lovely Professional

University, Phagwara (Punjab)

Research Interest: Material and Structure, Supply Chain

Management

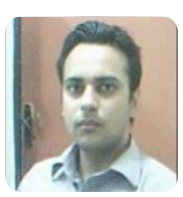

\section{Guravtar Singh Mann}

Designation: Associate Professor

Department: Industrial and Production Engineering

Qualification: M. Tech Industrial and Production Engineering (Dr. B. R Ambedkar NIT, Jalandhar), B.Tech Mechanical(PTU Jalandhar)

Research Interest: Green Composites, Biomedical Materials

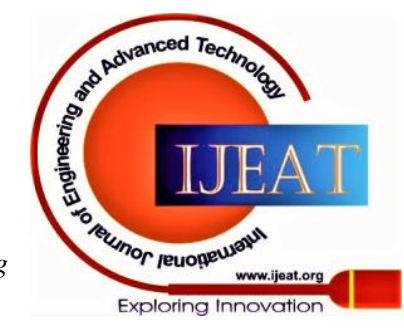

